Article

\title{
Governor Design for a Hydropower Plant with an Upstream Surge Tank by GA-Based Fuzzy Reduced-Order Sliding Mode
}

\author{
Chang $X u^{1, *, \dagger}$ and Dianwei Qian ${ }^{2,+}$ \\ Received: 28 August 2015; Accepted: 18 November 2015; Published: 26 November 2015 \\ Academic Editors: Ånund Killingtveit and Juan Ignacio Pérez-Díaz \\ 1 College of Energy and Electricity, Hohai University, No.1 Xikang Road, Gulou District, \\ Nanjing 210098, China \\ 2 School of Control and Computer Engineering, North China Electric Power University, No.2 Beinong Road, \\ Changping District, Beijing 102206, China; dianwei.qian@ncepu.edu.cn \\ * Correspondence: zhuifengxu@hhu.edu.cn; Tel.: +86-25-5278-9068; Fax: +86-25-8378-6510 \\ + These authors contributed equally to this work.
}

\begin{abstract}
This paper investigates governor design by reduced-order sliding mode for a hydropower plant with an upstream surge tank. The governing system is made up of a tunnel, a surge tank, a penstock, a wicket gate and servomechanism, a governor, a hydro-turbine and a grid. Concerning the components of the governing system, their mathematic models are established. Then, these models are interconnected to simulate the governing system. From the viewpoint of state space in modern control theory, the governing system is partially observed, which challenges the governor design. By introducing an additional state variable, the control method of reduced-order sliding mode is proposed, where the governor design is based on a reduced-order governing system. Since the governor is applied to the original governing system, the system stability is analyzed by means of the small gain theorem. An genetic algorithm is employed to search a group of parameters of the predefined sliding surface, and a fuzzy inference system is utilized to decrease the chattering problem. Some numerical simulations are illustrated to verify the feasibility and robustness of the control method.
\end{abstract}

Keywords: hydropower generation; governor; sliding mode control; order reduction; fuzzy logic; genetic algorithm

\section{Introduction}

With the coming of the low-carbon era, low-carbon power generation [1] is becoming increasingly significant and popular. Generally speaking, low-carbon power sources cover zero-emission thermal power generation, advanced atomic power generation, renewable energy, highly efficient electric power transmission, etc. As a kind of low-carbon power generation, hydropower, currently accounting for $19 \%$ of global electricity generated [2], offers an important low-carbon energy solution.

Hydropower uses hydraulic turbines to convert energy in flowing water into electricity. Such a source is one way of electrical generation from renewable potential sources. Usually, a hydropower plant is made up of the reservoir, water tunnel, surge tank, penstock, hydraulic turbine, speed governor, generator and grid [3]. Its sketch [4] is illustrated in Figure 1. In such a system, there exist strong couplings between hydraulic and mechano-electric dynamics. Moreover, the system has many different operating points [5]. Once the operating point changes, its characteristics will change. These undesired properties make its governor design challenging. 


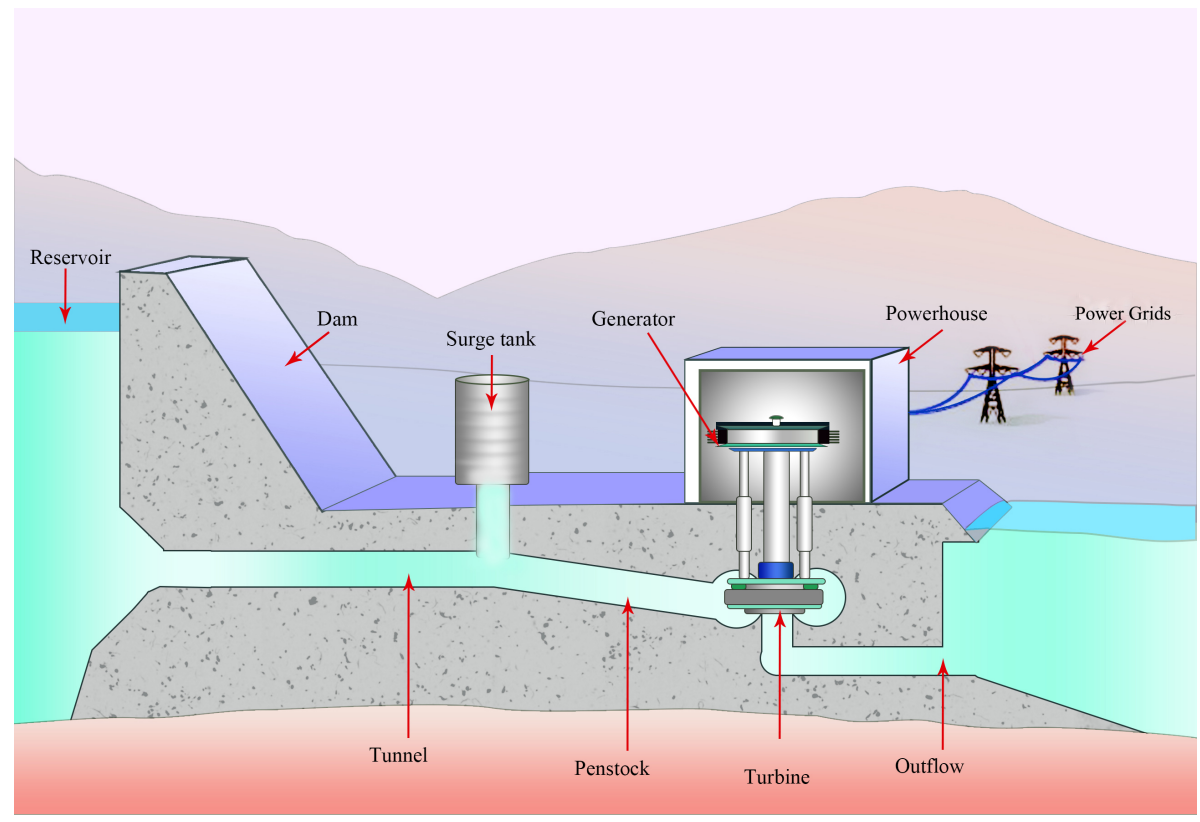

Figure 1. Sketch of a hydropower plant with an upstream surge tank.

In a governing system, control approaches are adopted to govern the hydro-turbine speed. Several approaches concerning the governor design problem have been reported in the last three decades. Two classes of governors can be roughly seen in this literature. The first class is the proportional integral derivative (PID) or PID-type governor [5-9]; the second class is the state feedback or intelligence-based governor [10-15].

Since the PID methodology only concentrates on system output and employs the information of the current error $(\mathrm{P})$, the sum of errors in history $(\mathrm{I})$ and the changing rate of error (D), the first class of governors may not make full use of the internal information of the governing system. Moreover, such a class is usually designed at the rated operating point and re-tuned for the worst operating point, so that the design does not ensure the stability of the governing system at all operating points. The second class of governors focuses on not only system output, but also a set of state variables representing the internal information of the governing system. With the development of advanced control technology, approaches, such as predictive control [10], intelligent method control [11], robust control [13-15] and multi-model control [16], are now being considered to facilitate the governor design of hydro-turbines.

Among various state space-based control methods, sliding mode control (SMC) with its discontinuous state-feedback control law provides a solution of variable structure control (VSC) [17]. The SMC method is an alternative to solve the speed control problem of hydro-turbines. In [18-20], the VSC methods with no sliding mode were taken into account for the problem. Compared to them, the SMC is superior, because the system performance is able to be tuned by designing a predefined sliding surface. To date, there has been rather rare literature about the SMC applications in this area.

There exist three issues concerning the SMC applications in the control problem. The first issue is how to pick up a set of measurable state variables for control design, because some state variables of the governing system are hard to measure in practice. The second one is how to select a group of suitable parameters of the predefined sliding surface, because the parameters are directly related to the dynamic performance of this control system. The third one is how to decrease the chattering phenomenon, an inner drawback of the SMC method, because high frequency chattering of the control signal is absolutely forbidden in the control problem.

In order to deal with the above issues in the governing speed of hydro-turbines, this paper presents an approach by means of the reduced-order SMC for a hydropower plant with an upstream 
surge tank. After modeling the governing system, a reduced-order sliding mode controller is proposed. The system stability is analyzed according to the small gain theorem. The genetic algorithm (GA) is employed to search a group of parameters of the predefined sliding surface, and a fuzzy inference system is built up to decrease the chattering problem by regulating the controller gain. To verify the feasibility and robustness of the control method, simulation results are illustrated. The remainder of this paper is organized as follows. In Section 2, the dynamics of the governing system are described. The GA-based fuzzy reduced-order sliding mode control law is designed in Section 3. The presented method in Section 4 is taken into account practically to verify the controller's feasibility and robustness. Finally, conclusions are drawn in Section 5.

\section{Dynamics of a Hydropower Plant with an Upstream Surge Tank}

A mathematic model is studied in [21] for a low-to-medium head plant with unrestricted head and tail race and either a very large or no surge tank. In the referred papers, most of them [6-20] take such a model as a benchmark. However, the model is simplified, and it neglects the effect of the surge tank on the accuracy. Though Fang et al. [5] investigated a mathematical model for hydropower plants with upstream and tail surge tanks, many hydropower plants do not have a surge tank at the tail tunnel. To develop a governor for hydropower plants with an upstream surge tank, it is necessary to model such a governing system [22-24].

Figure 2 displays a schematic diagram of hydropower plants with an upstream surge tank. The symbols in Figure 2 are determined by reservoir head $H_{R}(\mathrm{~m})$, tunnel length $L_{1}(\mathrm{~m})$, tunnel cross-section area $A_{1}\left(\mathrm{~m}^{2}\right)$, head of surge tank $H_{s}(\mathrm{~m})$, cross-section area of the surge tank $A_{s}\left(\mathrm{~m}^{2}\right)$, penstock length $L_{2}(\mathrm{~m})$, penstock cross-section area $A_{2}\left(\mathrm{~m}^{2}\right)$ and tail water head $H_{0}(\mathrm{~m})$. Both $H_{R}$ and $H_{0}$ are assumed to be constant. The conduits between the turbine and tail water lake are assumed to be of negligible length. The water in the surge tank is considered as being in steady flow conditions.

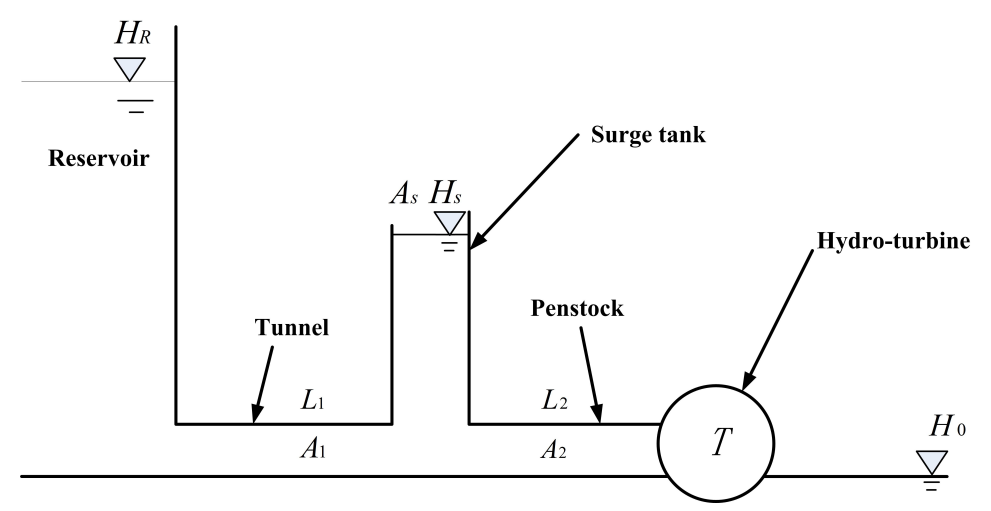

Figure 2. Schematic diagram of a hydropower plant with an upstream surge tank.

\subsection{Water Hammer}

For the components of the tunnel and penstock, they physically belong to the pipe flow in fluid dynamics. To model them, the classical mass and momentum equations for one-dimensional water hammer flows [25] are introduced as:

$$
\begin{gathered}
\frac{a^{2}}{g A} \frac{\partial Q}{\partial l}+\frac{\partial H}{\partial t}=0 \\
\frac{1}{A} \frac{\partial Q}{\partial t}+g \frac{\partial H}{\partial l}+\frac{4}{\rho D} \tau_{w}=0
\end{gathered}
$$

where $a\left(\mathrm{~m} \cdot \mathrm{s}^{-1}\right)$ is acoustic (water hammer) wave speed, $H(\mathrm{~m})$ is the piezometric head, $A\left(\mathrm{~m}^{2}\right)$ is the cross-sectional area of the pipe, $Q\left(\mathrm{~m}^{3} \cdot \mathrm{s}^{-1}\right)$ is the cross-sectional average flow rate, 
$g=9.81 \mathrm{~m} \cdot \mathrm{s}^{-2}$ is the gravitational acceleration, $D(\mathrm{~m})$ is the pipe diameter, $\rho\left(\mathrm{kg} \cdot \mathrm{m}^{-3}\right)$ is the water density, $\tau_{w}\left(\mathrm{~N} \cdot \mathrm{m}^{-2}\right)$ is the shear stress at the pipe wall, $l$ is the spatial coordinate along the pipeline and $t$ is the temporal coordinate. According to the Darcy-Weisbach equation [25], we have:

$$
\tau_{w}=\frac{\rho f\|Q\| Q}{8 A^{2}}
$$

Here, $f$ is the Darcy-Weisbach friction factor. If the flow rate $Q$ from left to right is defined as a positive direction, then we have Equation (4) by substituting Equation (3) into Equation (2).

$$
\frac{1}{A} \frac{\partial Q}{\partial t}+g \frac{\partial H}{\partial l}+\frac{f Q^{2}}{2 g D A^{2}}=0
$$

Apparently, $Q$ and $H$ in Equation (1) and Equation (4) couple with each other according to the viewpoint of control theory. From Equation (1) and Equation (4), the water-hammer model [26] is formulated as:

$$
\frac{\mathscr{L}[\mathfrak{h}(t)]}{\mathscr{L}[\mathbb{q}(t)]}=-2 \cdot \frac{T_{w}}{T_{r}} \cdot \tanh \left(\frac{T_{r} s}{2}+\frac{T_{r} H_{f}}{2 T_{w}}\right)
$$

where $\mathbb{h}$ (per unit) is the water head relative deviation of the pipe inlet and outlet, $\mathbb{q}$ (per unit) is the flow rate relative deviation of the pipe inlet and outlet, $T_{r}$ (s) is the penstock water reflection time, $T_{w}(\mathrm{~s})$ is the water inertia time, $H_{f}$ is the hydraulic loss, $s$ is the complex variable in the Laplace domain and $\mathscr{L}[\cdot]$ denotes the Laplace transfer. $T_{w}(\mathrm{~s})$ is defined as $\frac{L Q_{r}}{g A H_{r}}$, where $A\left(\mathrm{~m}^{2}\right)$ is the cross-section area of the pipe, $H_{r}(\mathrm{~m})$ is the rated head, $Q_{r}\left(\mathrm{~m}^{3} \cdot \mathrm{s}^{-1}\right)$ is the rated flow rate and $L(\mathrm{~m})$ is the pipe length.

\subsection{Tunnel}

In Figure 2, the water tunnel joins the reservoir and surge tank together. Provided that the incompressible conditions are generally satisfied in the tunnel $L_{1}$, Equation (6) can be deduced from Equation (5) under the assumption of the inelastic water hammer effect.

$$
\frac{\mathscr{L}\left[h_{1}(t)\right]}{\mathscr{L}\left[q_{1}(t)\right]}=-T_{w 1} s-H_{f 1}
$$

where $h_{1}$ (per unit) is the head deviation of the tunnel input and output, $q_{1}$ (per unit) is the flow rate deviation of the tunnel input and output, $H_{f 1}$ is the hydraulic loss in the tunnel and $T_{w 1}(\mathrm{~s})$ is the water inertia time of the tunnel, defined as $\frac{L_{1} Q_{r}}{g A_{1} H_{r}}$.

\subsection{Penstock}

In Figure 2, the penstock joins the surge tank and tail water lake together. Provided that the incompressible conditions are generally satisfied in the penstock, Equation (7) can also be deduced from Equation (5) under the assumption of the inelastic water hammer effect.

$$
\frac{\mathscr{L}\left[h_{2}(t)\right]}{\mathscr{L}\left[q_{2}(t)\right]}=-T_{w 2} s-H_{f 2}
$$

where $h_{2}$ (per unit) is the head deviation of the penstock input and output, $q_{2}$ (per unit) is the flow rate deviation of the penstock input and output, $H_{f 2}$ is the hydraulic loss in the penstock and $T_{w 22}(\mathrm{~s})$ is the water inertia time of the penstock, defined as $\frac{L_{2} Q_{r}}{g A_{2} H_{r}}$. 


\subsection{Surge Tank}

Usually, the length of surge tank is much shorter than the length of the penstock and tunnel, so that hydraulic losses at the orifices of the surge tank are neglected. The surge tank Equation (8) can be derived from the continuity of flow at two junctions.

$$
T_{s} \frac{\mathrm{d} h_{s}}{\mathrm{~d} t}=q_{s}
$$

where $h_{s}$ (per unit) is the water head deviation of the surge tank, $q_{s}$ (per unit) is the flow deviation of the surge tank and $T_{s}=\frac{A_{s} H_{r}}{Q_{r}}(\mathrm{~s})$ is the filling time of the surge tank.

\subsection{Wicket Gate and Servomechanism}

Gate movement is driven by a hydraulic system. The transfer function between the control signal $u$ and the wicket gate servomotor stroke $y$ can be expressed by a first-order equation, written as:

$$
\frac{\mathscr{L}[y(t)]}{\mathscr{L}[u(t)]}=\frac{1}{T_{y} s+1}
$$

here, $T_{y}(\mathrm{~s})$ is the response time of the wicket gate servomotor.

\subsection{Hydro-Turbine}

In references [5,27], the linearized small-signal model of ideal Francis turbines is formulated by:

$$
\begin{aligned}
m & =e_{x} x+e_{y} y+e_{h} h \\
q & =e_{q x} x+e_{q y} y+e_{q h} h
\end{aligned}
$$

where $m$ (per unit) is the turbine torque relative deviation, $q$ (per unit) is the turbine flow rate relative deviation, $h$ (per unit) is the turbine water head relative deviation, $x$ (per unit) is the turbine speed relative deviation and $y$ (per unit) is the wicket gate servomotor stroke relative deviation. In Equation (10), the six coefficients for Francis turbines are determined by $e_{x}=\frac{\partial\left(M / M_{r}\right)}{\partial\left(X / X_{r}\right)}$, $e_{y}=\frac{\partial\left(M / M_{r}\right)}{\partial\left(G_{t} / G_{\max }\right)}, e_{h}=\frac{\partial\left(M / M_{r}\right)}{\partial\left(H / H_{r}\right)}, e_{q x}=\frac{\partial\left(Q / Q_{r}\right)}{\partial\left(X / X_{r}\right)}, e_{q y}=\frac{\partial\left(Q / Q_{r}\right)}{\partial G_{t} / G_{\max }}$ and $e_{q h}=\frac{\partial\left(Q / Q_{r}\right)}{\partial\left(H / H_{r}\right)} ;$ here, $M_{r}(\mathrm{kN} \cdot \mathrm{m})$ and $X_{r}(\mathrm{r} / \mathrm{min})$ are the rated turbine torque and rated speed, and $G_{\max }(\mathrm{mm})$ is the maximum equivalent gate position. The coefficients in Equation (10) can be calculated at each operating point.

\subsection{Generator and Grid}

Provided that there is no other generation source except a plant in one grid, i.e., a single-machine infinite-bus power system, the small-signal model of the generator and grid component [5] has the form of:

$$
\frac{\mathscr{L}[x(t)]}{\mathscr{L}\left[m(t)-m_{g 0}\right]}=\frac{1}{T_{a} s+e_{g}}
$$

here, $T_{a}(\mathrm{~s})$ is the generator unit mechanical time, and $e_{g}$ is the rotational loss coefficient. $T_{a}$ is determined by $\frac{J_{g} X_{r}^{2}}{3580 P_{r}} \times 10^{-3}$, where $J_{g}\left(\mathrm{kN} \cdot \mathrm{m}^{2}\right)$ is the generator unit inertia torque, $P_{r}(\mathrm{~kW})$ is the generator-rated power output and $X_{r}(\mathrm{r} / \mathrm{min})$ is the rated speed.

The differential Equations (6)-(9), Equation (11) and the algebraic Equation (10) form the individual component model of hydropower plants with an upstream surge tank driven by a Francis turbine. By interconnecting these components together, a block diagram of the governing system is displayed in Figure 3. In Figure 3, the green solid line denotes the hydro-turbine part, the yellow solid line denotes the penstock part, the pink solid line denotes the surge tank part, the red solid line denotes the generator and grid part, the blue solid lines denotes the wicket gate and servomechanism part and the dashed line will be mentioned below. 


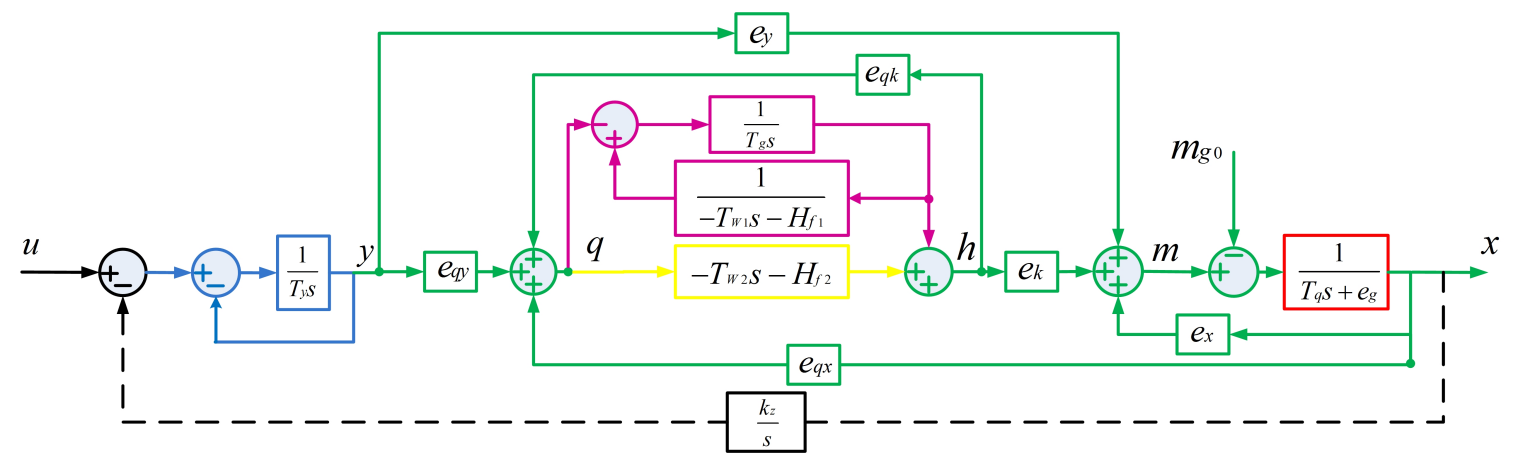

Figure 3. Block diagram of the hydropower plants with an upstream surge tank.

\section{Control Design}

With the development of sensor and measuring technology, many methods have been raised to obtain internal information from an industrial process. This extends the ability of control design. As far as the governing system of hydropower plants with an upstream surge tank is concerned, we have obtained the system model as a fourth-order ordinary differential equation (except the dashed-line part in Figure 3). The model indicates that four independent state variables can depict the governing system in state space from the viewpoint of modern control theory. In Figure 3, it is obvious that the governing system is partly observed. The measurable variables are $y, q, h, m$ and $x$. However, they are a linear correlation in Equation (10), which indicates that only three independent and measurable variables among them are available in the governing system. Here arises the challenging problem of how to develop a controller by the limited number of measurable and independent state variables.

\subsection{Design of the Reduced-Order Sliding Mode Controller}

Due to the advantages that SMC possesses, we intend to design a sliding mode controller for the governing system. In this subsection, a reduced-order sliding mode controller is gradually taken into account via the independent and measurable state variables $y, m$ and $x$.

To force the steady value of $x$ to zero, the integral of $x$ is defined as an additional state $x_{4}$ with a known gain $K_{E}$ [28]. The expression of the state is written as:

$$
x_{4}=K_{E} \int_{0}^{\infty} x \mathrm{~d} t
$$

The additional-state component is shown by the dashed line in Figure 3. Then, the sliding surface takes the form:

$$
S=\mathbf{c}^{T} \mathbf{x}
$$

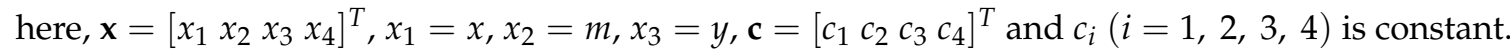

Generally speaking, the SMC law includes two parts: the switching control law and the equivalent control law [17]. The switching control law is employed to drive the system states moving towards the predefined sliding surface. The equivalent control law guarantees the system states keep sliding on the surface and converge to the desired value along the surface. We still adopt such an idea to design the reduced-order sliding mode controller and define the control law $u$ as:

$$
u=u_{e q}+u_{s w}
$$

here, $u_{s w}$ is the switching control, and $u_{e q}$ is the equivalent control law. Their expressions are deduced below. In Equation (14), $u_{e q}$ and $u_{s w}$ are model-based, so that we have to obtain a simplified model 
described by the three independent and measurable state variables. This is also the reason that we name the controller "reduced-order sliding mode".

As shown in Figure 3, the wicket gate and servomechanism component is depicted by a first-order equation with the state $x_{3}$; the generator and grid component is also depicted by a first-order equation with the state $x_{1}$; and the turbine component is depicted by an algebraic equation. To get a reduced-order model depicted by the limited state variables, we have to analyze the remaining components, i.e., the tunnel, the surge tank and the penstock. In Figure 3, the transfer function of the three components can be written as:

$$
G_{2}^{0}(s)=\frac{\mathscr{L}[h(t)]}{\mathscr{L}[q(t)]}=-\frac{T_{w 1} s+H_{f 1}}{\left(T_{w 1} s+H_{f 1}\right) T_{s} s+1}-T_{w 2} s-H_{f 2}
$$

We know that the function of the surge tank is to absorb the sudden rises of pressure, as well as to quickly provide extra water during a brief drop in pressure. The position of the surge tank is usually nearer to the power plant than to the reservoir. This fact indicates that $T_{w 1}$ is usually larger or much larger than $T_{w 22}$ in Equation (15). Thus, one method to reduce the order of Equation (15) is to use the steady value of the unit step response of the first term on the right of Equation (15) instead of its original expression, and other two terms are kept unchanged. Along the route, the reduced-order expression of the three components can be described by a first-order equation with the state $x_{2}$ as:

$$
G_{2 r}^{0}(s)=\frac{\mathscr{L}\left[h_{r}(t)\right]}{\mathscr{L}\left[q_{r}(t)\right]}=-T_{w 2} s-H_{f 2}-H_{f 1}
$$

note that the simplified model Equation (16) is only for the following control design. The original model Equation (15) will be still held as the controlled plant. Finally, the reduced-order model of the governing system in state space can be depicted as:

$$
\begin{aligned}
& \dot{\mathbf{x}}=\mathbb{A} \mathbf{x}+\mathbb{B} u+\mathbb{F} d(t) \\
& y=\mathbb{C}^{T} \mathbf{x}
\end{aligned}
$$

here, $\mathbf{x}=\left[\begin{array}{llll}x_{1} & x_{2} & x_{3} & x_{4}\end{array}\right]^{T}$ is the state vector, and $d(t)$ is the signal of the load disturbance; the state matrix $\mathbb{A}$, input vector $\mathbb{B}$, output vector $\mathbb{C}$ and disturbance vector $\mathbb{F}$ are shown in Appendix $A$.

According to the SMC methodology, only the equivalent control $u_{e q}$ works when the system states keep sliding on the sliding surface. Differentiate $S$ with respect to time $t$ in Equation (13); let $\dot{S}=0$; and substitute the nominal model of Equation (17) into $\dot{S}=0$. Then, we can obtain:

$$
u_{e q}=-\left(\mathbf{c}^{T} \mathbb{B}\right)^{-1} \mathbf{c}^{T} \mathbb{A} \mathbf{x}
$$

In order to ensure that the total control law Equation (14) makes the sliding surface Equation (13) asymptotically stable, we define a Lyapunov function as:

$$
V(t)=\frac{1}{2} S^{2}
$$

differentiate $V$ with respect to $t$ and substitute Equations (13), (14), (17) and (18) into $\dot{V}$. Then, we have:

$$
\begin{aligned}
\frac{\mathrm{d} V}{\mathrm{~d} t} & =S \dot{S}=S\left[\mathbf{c}^{T} \dot{\mathbf{x}}\right] \\
& =S\left[\mathbf{c}^{T}\left(\mathbb{A} \mathbf{x}+\mathbb{B} u+\mathbf{c}^{T} \mathbb{F} d(t)\right)\right] \\
& =S\left\{\mathbf{c}^{T}\left[\mathbb{A} \mathbf{x}+\mathbb{B}\left(u_{e q}+u_{s w}\right)+\mathbf{c}^{T} \mathbb{F} d(t)\right]\right\} \\
& =S\left[\mathbf{c}^{T}\left(\mathbb{A} \mathbf{x}+\mathbb{B} u_{e q}\right)+\mathbf{c}^{T} \mathbb{B} u_{s w}+\mathbf{c}^{T} \mathbb{F} d(t)\right] \\
& =S\left[\mathbf{c}^{T} \mathbb{B} u_{s w}+\mathbf{c}^{T} \mathbb{F} d(t)\right]
\end{aligned}
$$


Let $\mathbf{c}^{T} \mathbb{B} u_{s w}=-\kappa S-\eta \operatorname{sgn}(S)$ where $\kappa$ and $\eta$ are positive constants and $\operatorname{sgn}(\cdot)$ is a sign function; the switching control law $u_{s w}$ is obtained as:

$$
u_{s w}=-\left(\mathbf{c}^{T} \mathbb{B}\right)^{-1}[\kappa S+\eta \operatorname{sgn}(S)]
$$

From Equation (14), the control law $u$ is finally deduced as:

$$
u=u_{e q}+u_{s w}=-\left(\mathbf{c}^{T} \mathbb{B}\right)^{-1}\left[\mathbf{c}^{T} \mathbb{A} \mathbf{x}+\kappa S+\eta \operatorname{sgn}(S)\right]
$$

Further, Equation (20) becomes:

$$
\begin{aligned}
\frac{\mathrm{d} V}{\mathrm{~d} t} & =S\left[-\kappa S-\eta \operatorname{sgn}(S)+\mathbf{c}^{T} \mathbb{F} d(t)\right] \\
& \leq-\kappa S^{2}-\eta|S|+|S| \cdot\left|\mathbf{c}^{T} \mathbb{F} d(t)\right| \\
& \leq-\kappa S^{2}-\left[\eta-\left|\mathbf{c}^{T} \mathbb{F} d(t)\right|\right] \cdot|S|
\end{aligned}
$$

Define $\mathbb{D}_{M}=\sup \left|\mathbf{c}^{T} \mathbb{F} d(t)\right|$. If $\eta>\mathbb{D}_{M}$ is satisfied, we have $\frac{\mathrm{d} V}{\mathrm{~d} t} \leq-\kappa S^{2}-\left(\eta-\mathbb{D}_{M}\right)|S|<0$ in Equation (23), so that the reduced-order governing system Equation (17) possesses the asymptotic stability under the control law Equation (22) in the sense of Lyapunov. However, the control law Equation (22) will be applied to the original system. Consequently, it is necessary to analyze whether the reduced-order sliding mode controller is able to stabilize the original system or not.

Theorem 3.1: If Equation (24) is satisfied, then the reduced-order sliding mode control law Equation (22) is able to stabilize the original system, as well.

$$
\left\|1-\frac{G_{2}}{G_{2 r}}\right\|_{\infty} \leq\left(\left\|\frac{G(s)}{1-G(s)}\right\|_{\infty}\right)^{-1}
$$

here, $G_{2}(s)=e_{q y} \frac{G_{2}^{0}(s)}{1-e_{q h} G_{2}^{0}(s)} e_{h}+e_{y}, G_{2 r}(s)=e_{q y} \frac{G_{2 r}^{0}(s)}{1-e_{q h} G_{2 r}^{0}(s)} e_{h}+e_{y}, G(s)=G_{1}(s) G_{2 r}(s) G_{3}(s) G_{4}(s)$, $G_{1}(s)=\frac{1}{T_{y} s+1}$ and $G_{3}(s)=\frac{1}{T_{a} s+e_{g}-e_{x}}, G_{4}(s)=-\frac{K_{E}}{s}$.

Proof. See Appendix B.

Comment: (1) Though the reduced-order sliding mode controller can make the original system stable, the sliding mode just takes place in the reduced-order system. The reduced-order system is in a subspace of the original one. In this sense, the reduced-order sliding mode control system is not as robust as the full-state feedback sliding mode control system, because the sliding mode just exists in a subspace of the original system. (2) To regulate the error of each state to zero in state space, we have to foresee the desired value of each state. In fact, it is difficult to know the desired values of all states in the governing system although the current values of all states are measurable. Thus, the additional state is introduced to force all states to tend to be stable. Owing to the existence of the integral term on the sliding surface, the reduced-order sliding mode controller belongs to the integral $\mathrm{SMC}$ in this sense.

\subsection{GA-Based Parameter Optimization}

The parameters of the sliding surface in Equation (13) are related to the system performance. However, it is a time-consuming task to select them by trial and error tuning, since the response curves are very sensitive to them. The genetic algorithm (GA) is a searching strategy inspired by natural evolution behavior [29]. Each individual consisting of a set of parameters to be tuned can be represented by a chromosome. A simple GA includes individual selection, mutation and crossover steps. The selection from the whole population is based on each individual's fitness. A roulette selection strategy is adopted in the following comparison. The mutation causes a complete opposite change on the gene bit randomly. The crossover exchanges part of the information between two 
individuals. After the genetic operation, new individuals are generated to form a new population. The fitness mapping is a key problem for the genetic learning process. The reciprocal of the integral squared error (ISE) of all state variables in the reduced-order model is selected as the individual fitness:

$$
J=\frac{1}{\int_{0}^{\infty}\left[x_{1}^{2}(t)+x_{2}^{2}(t)+x_{3}^{2}(t)+x_{4}^{2}(t)\right] \mathrm{d} t}
$$

A good individual corresponds to a big fitness. As the genetic operation goes on, the individual maximum fitness and the population average fitness are increased steadily. We find that the parameters can be searched out by the simple GA, but they vary greatly with different crossover probability, mutation probability and population size. The parameters often converge to different results in different experiments, which may not be an optimized solution. Some improvements are proposed on the basis of the simple GA. Large crossover probability and small mutation probability will ensure population diversities and prevent premature convergence of maximum individual fitness, so that the crossover fraction and mutation fraction are set to 0.95 and 0.05 , respectively. Elitist individual reservation is applied to ensure that the maximum fitness continues to increase, and the reservation will prevent the fluctuation of the maximum fitness caused by large crossover probabilities. On the other hand, when the sliding mode takes place in Equation (17), we have:

$$
\dot{\mathbf{x}}=\mathbb{A} \mathbf{x}+\mathbb{B} u_{e q}=\left[\mathbb{A}-\mathbb{B}\left(\mathbf{c}^{T} \mathbb{B}\right)^{-1} \mathbf{c}^{T} \mathbb{A}\right] \mathbf{x}
$$

All of the eigenvalues of $\mathbb{A}-\mathbb{B}\left(\mathbf{c}^{T} \mathbb{B}\right)^{-1} \mathbf{c}^{T} \mathbb{A}$ should have negative real parts on the aspect of system stability. The condition is treated as a constraint, and $\kappa$ and $\eta$ are fixed to accelerate the searching process.

\subsection{Design of the Fuzzy Inference System}

Fusing the prior knowledge about the SMC, we know that a large value of $\kappa$ is needed if the system states are far from the sliding surface. On the other side, a small $\kappa$ is needed. On account of the reachability condition of the SMC [17], the sliding surface variable $S$ times its first-order derivative $\frac{\mathrm{d} S}{\mathrm{~d} t}$ is chosen as the input variable, and the change of $k$, i.e. $\Delta \kappa$, is chosen as the output variable. The if-then rule base of this fuzzy inference system is designed as:

- If $S \dot{S}$ is $\mathrm{PB}$, then $\Delta \kappa$ is $\mathrm{PB}$.

- If $S \dot{S}$ is $P M$, then $\Delta \kappa$ is $P M$.

- If $S \dot{S}$ is $\mathrm{Z}$, then $\Delta \kappa$ is $\mathrm{Z}$.

- If $S \dot{S}$ is $\mathrm{NM}$, then $\Delta \kappa$ is $\mathrm{NM}$.

- If $S \dot{S}$ is $\mathrm{NB}$, then $\Delta \kappa$ is $\mathrm{NB}$.

where NB, NM, Z, PM, PB are negative big, negative medium, zero, positive medium and positive big, respectively. The membership functions of linguistic labels NB, NM, Z, PM, PB for $s \dot{s}$ and $\Delta \kappa$ are shown in Figure $4 \mathrm{a}$, where $m_{0}$ and $m_{1}$ are constant. Figure $4 \mathrm{~b}$ shows the output surface of the designed fuzzy inference system using the input $s \dot{s}$ and the output $\Delta \kappa$. The final value of $\kappa$ regulated by the fuzzy logic is determined by:

$$
\kappa=\kappa_{0}+\Delta \kappa
$$

here, $\kappa_{0}$ is a basic value. 

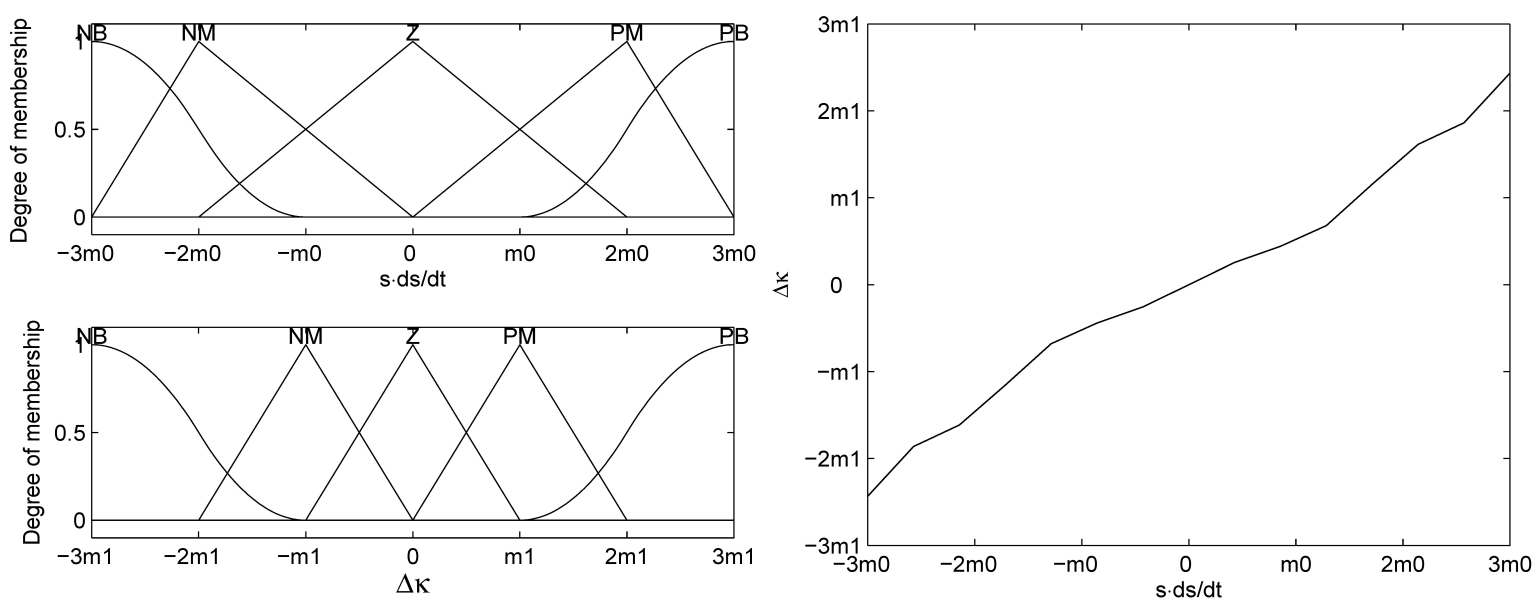

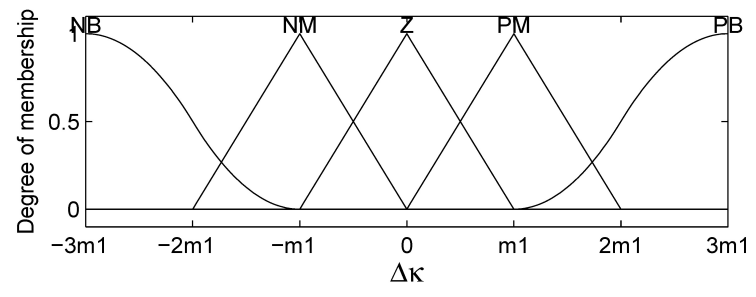

(a)

(b)

Figure 4. (a) Membership functions of the linguist labels; (b) Output surface of the fuzzy inference system.

\section{Simulation Results}

Lubuge hydropower plant, with a rated head of $312.0 \mathrm{~m}$ and a maximum net head $372.5 \mathrm{~m}$, is on Huangni River where Yunnan and Guizhou provinces border Guangxi Zhuang Autonomous Region, China. The installments of this plant are $4 \times 153$ MW Francis turbines. The diversion system consists of a pressure tunnel of $9387 \mathrm{~m}$ in length and $8 \mathrm{~m}$ in diameter, a surge tank of $12 \mathrm{~m}$ in inner diameter and $63.9 \mathrm{~m}$ in height, two penstocks of $470 \mathrm{~m}$ in length and $4.6 \mathrm{~m}$ in diameter and four branches of $3.2 \mathrm{~m}$ in diameter. Since the branches are very short, we simplify the branch model as hydraulic losses. The data of the plant are employed to simulate load rejection. The data are determined by $P_{r}=153 \mathrm{MW}, H_{r}=312.0 \mathrm{~m}, Q_{r}=53.5 \mathrm{~m}^{3}, X_{r}=333.3 \mathrm{r} / \mathrm{min}, L_{1}=9387 \mathrm{~m}, A_{1}=49.6 \mathrm{~m}^{2}$, $A_{s}=113.04 \mathrm{~m}^{2}, L_{2}=470 \mathrm{~m}, A_{2}=16.61 \mathrm{~m}^{2}, J_{g}=4.0 \times 10^{4} \mathrm{kN} \cdot \mathrm{m}^{2}$. The mathematic model in Section 2 is able to depict the operating condition in which one turbine is fed by one penstock. Under such an operating condition, $H_{f 1}=0.036$ and $H_{f 2}=0.027$. The time constants $T_{a}, T_{y}, T_{W 1}$, $T_{W 2}$ and $T_{S}$ are $8.113,0.500,3.312,1.244$ and $659.224 \mathrm{~s}$, respectively. Turbine coefficients under the operating points of Case 1 and Case 2 are determined in Table 1 . A value of 0.200 is picked for $K_{E}$, the gain of the additional state. The parameter vector of the sliding surface on the operating point of Case 1 is optimized by the improved GA as $\mathbf{c}=\left[\begin{array}{llll}500 & 35 & 63 & 600\end{array}\right]^{T}$. The parameters of the fuzzy inference system are set as $m_{0}=2$ and $m_{1}=\frac{1}{3}$. Since $\min \Delta \kappa=-1, \kappa_{0}$ and $\eta$ are selected as one and 0.5 from the viewpoint of the system stability in Equation (23).

Table 1. Turbine coefficients on two steady-state operating points.

\begin{tabular}{cccccccc}
\hline Coefficients & $\boldsymbol{e}_{\boldsymbol{x}}$ & $\boldsymbol{e}_{\boldsymbol{y}}$ & $\boldsymbol{e}_{\boldsymbol{h}}$ & $\boldsymbol{e}_{\boldsymbol{q} \boldsymbol{x}}$ & $\boldsymbol{e}_{\boldsymbol{q} \boldsymbol{y}}$ & $\boldsymbol{e}_{\boldsymbol{q} \boldsymbol{h}}$ & $\boldsymbol{e}_{\boldsymbol{g}}$ \\
\hline Case 1 & -1.000 & 1.000 & 1.500 & 0.000 & 1.000 & 0.500 & 0.210 \\
Case 2 & -0.260 & 0.322 & 0.722 & 0.000 & 0.573 & 0.325 & 0.210 \\
\hline
\end{tabular}

To verify the validity of the reduced-order model, comparisons by Bode plots are shown in Figure 5. In Figure 5a, the simplified components of the tunnel, surge tank and penstock are able to be treated as the asymptotical plot of the original ones. At middle frequencies, the plots of the simplified system are smoother in Figure 5a. It can be treated as the mean of the original components at these frequencies. Figure $5 \mathrm{~b}$ shows the simplified and original plots of the whole governing system. In Figure $5 \mathrm{~b}$, the two plots are almost the same type as each other. This indicates that the reduced-order 
model is valid with desired accuracy to depict the original governing system. Further, Equation (24) is satisfied.

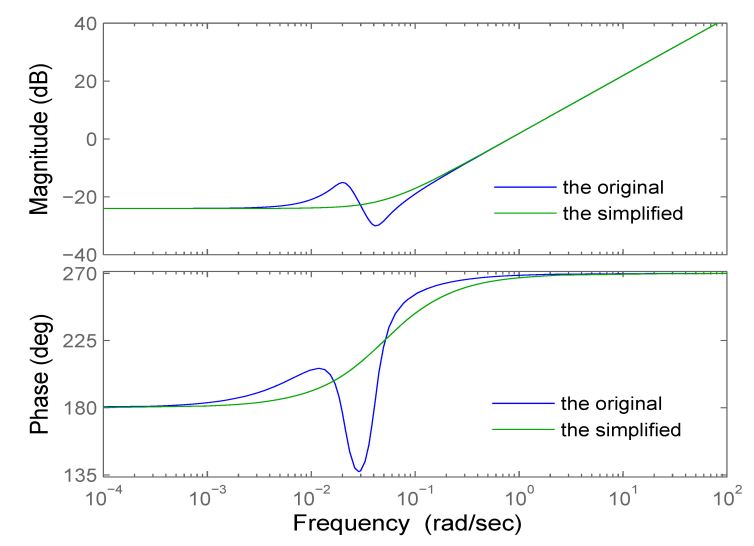

(a)

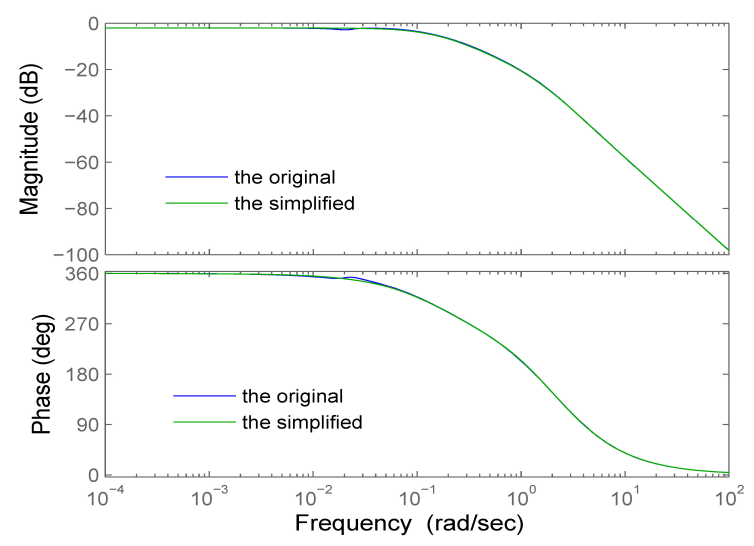

(b)

Figure 5. Bode plots. (a) The simplified components; (b) The whole governing system.

\subsection{Load Rejection}

Load rejection in an electric power system means a sudden load trip in the system, which causes the generation side to be over frequency. Figure 6 illustrates the comparison of 10\% load rejection on the operating point of Case 1 among the GA-based fuzzy reduced-order SMC governor, the robust PID governor tuned by internal mode control (IMC) and the PID governor tuned by trial and error. The PID governors have the form $u(t)=K_{p} x(t)+K_{i} \int x(t) \mathrm{d} t+K_{d} \dot{x}(t)$. The gains via IMC tuning are determined by $K_{p}=4.3086, K_{i}=0.8938$ and $K_{d}=2.8925$ [30]. Another set of gains $K_{p}=0.89$, $K_{i}=0.30$ and $K_{d}=2.00$ are selected by trial and error [31].

Displayed in Figure 6, the reduced-order sliding mode governor possesses better performance than the two PID governors from the viewpoint of speed deviations $x$. The wicket gate deviation $y$ under the action of the reduced-order SMC governor can respond the minute that the load changes. Correspondingly, the flow deviation $q$ is changed to regulate the power output so that the speed deviation $x$ can be eliminated as soon as possible. On the other hand, the performances of $u$ and $m$ do not seem very good, since their overshoots are larger under the action of the reduced-order SMC governor. Associated with the process of hydroelectric generation, this fact indicates that the control signal $u$ orders the turbine torque deviation $m$ as soon and as much as possible to reject the load disturbance $m_{g 0}$ once the disturbance is injected into the governing system. All of the system states coordinate each other to make the whole governing system respond faster and better under the action of the reduced-order SMC governor, as shown in Figure 6. Further, we can also explain the reason that the presented control method possesses better performance from the viewpoint of information. The reduced-order SMC governor makes full use of the measurable information of the governing system to decide the final control input, whereas the two PID governors just employ the proportional, integral and derivative of $x$ to formulate the final control input, only utilizing a limited part of the system information. 

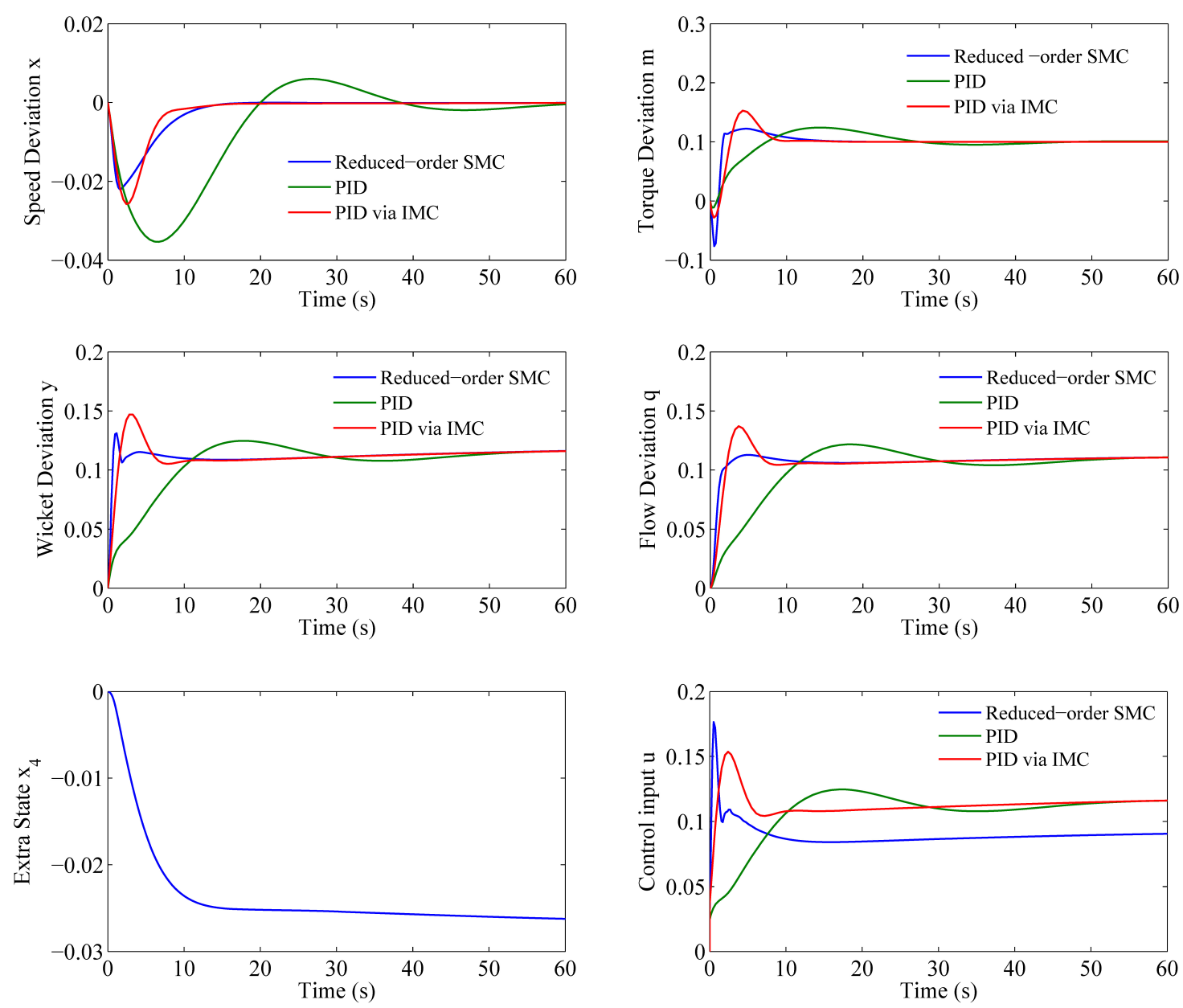

Figure 6. Simulation results of $10 \%$ load rejection on the operating point of Case 1 by the reduced-order sliding mode control (SMC) governor, compared to two PID governors.

\subsection{Robustness Testing}

To verify the robustness of the reduced-order SMC governor, the parameters on the operating point of Case 2 are employed as testing data. Since the reduced-order SMC governor is designed on the operating point of Case 1, this simulation can examine the controller's robustness. In the simulation, the controller parameters are kept unchanged from the operating point of Case 1, but the turbine parameters are set as the operating point of Case 2. This study can illustrate the system performance under the action of the reduced-order sliding mode governor when the operating points are changed.

The results are displayed in Figures 7 and 8, respectively. Shown by the red solid line in Figure 7, the reduced-order SMC governor still works, even though the operating point has been changed, and the system performance is still acceptable to resist 10\% load disturbance. This fact illustrates that the reduced-order SMC governor is robust to resisting the change of operating points. Figure 8 plots the output of the designed fuzzy inference system (FIS) on the two operating points. On the operating point of Case 1, the FIS output is smooth. When the operating point is shifted to another one, the FIS output frequently switches to maintain the system performance as well as possible in Figure 8. Although the FIS output has the chattering phenomenon, the control input $u$ in Figure 7 is still smooth. This indicates that the FIS works as a soft switcher instead of the traditional hard switcher of the control input $u$. 

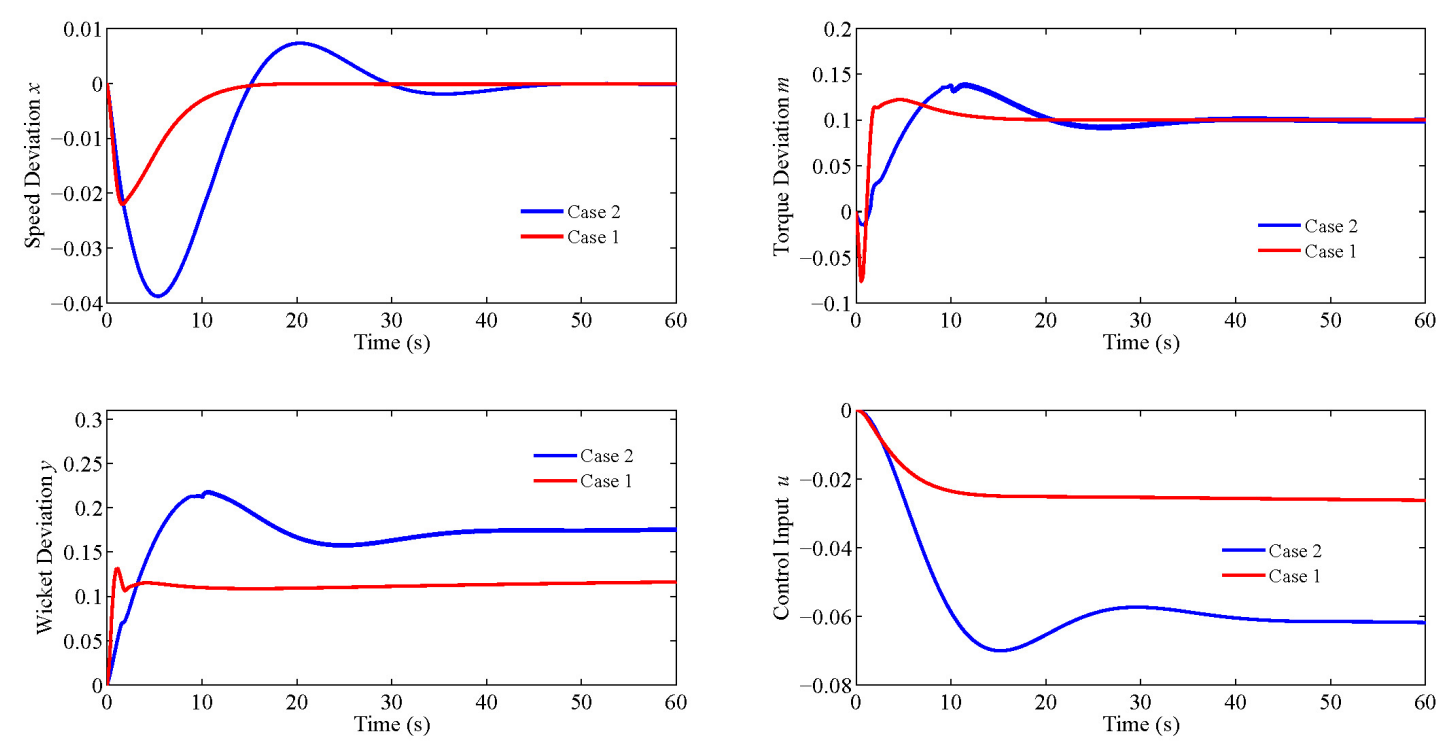

Figure 7. Simulation results of robustness testing under different operating points.
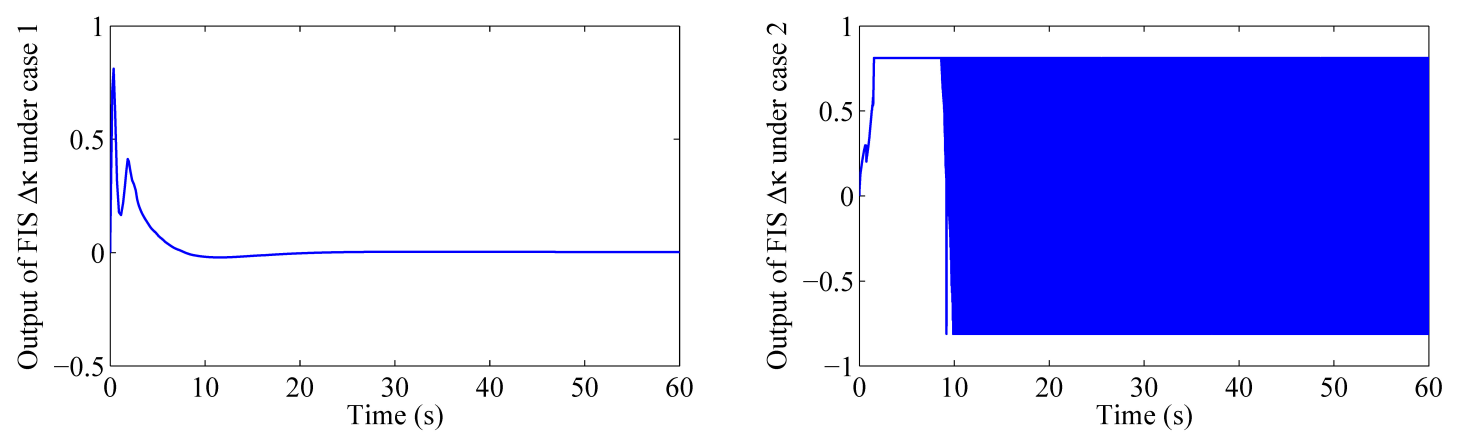

Figure 8. Fuzzy inference system (FIS) output under different operating points.

\section{Conclusions}

This paper has presented a GA-based fuzzy reduced-order sliding mode controller to govern the hydro-turbine speed for a hydropower plant with an upstream surge tank. To achieve this purpose, the dynamic model of the governing system was firstly established. Since the state variables of the governing system were partly observed, the method of reduced-order SMC was presented by introducing an additional state variable. A sufficient condition for how to stabilize the original system by the reduced-order controller was proven in terms of the small gain theorem. To optimize parameters of the sliding surface, an improved GA was employed. To decrease chattering, an FIS was designed to regulate the controller gain according to the reachability condition of the SMC. Finally, simulation results illustrated the feasibility and robustness of the method. The application of the method to a testbed is still in progress.

Acknowledgments: This work is financially supported by the International Science and Technology Cooperation Project between China and Denmark under Grant No.2014DFG62530; the Jiangsu Province Natural Science Fund under grant No.BK20131369; the State Grid Science and Technology project (Wind turbine intelligent control technology research and demonstration); the Nantong Science and Technology Project under Grant No.BK2014028 and the Fundamental Research Funds for the Central Universities under Grant No.2015MS29 at North China Electric Power University.

Author Contributions: Chang $\mathrm{Xu}$ was responsible for modeling the governing system and the order reduction, and Dianwei Qian took charge of the stability analysis and did the numerical simulations. 
Conflicts of Interest: The authors declare no conflict of interest.

\section{Appendix}

Appendix A. Reduced-Order Model

Define $\Gamma=H_{f 1}+H_{f 2}, \Lambda=-\frac{T_{w 2}}{T_{y}}\left(e_{q y} e_{h}-e_{q h} e_{y}\right), \Delta=1+e_{q h} \Gamma$ and $Y=-\frac{T_{w 2}}{T_{a}} e_{q h} e_{x}$. Then, $\mathbb{A}, \mathbb{B}$, $\mathbb{C}$ and $\mathbb{F}$ in Equation (17) are determined by:

$$
\begin{aligned}
& \mathbb{A}=\left[\begin{array}{cccc}
-\frac{e_{g}}{T_{a}} & \frac{1}{T_{a}} & 0 & 0 \\
e_{g} Y+e_{x} \Delta & \mathrm{Y}-\Delta & \Lambda+e_{y} \Delta-e_{h} e_{q y} \Lambda & \Lambda \\
0 & 0 & -\frac{1}{T_{y}} & -\frac{1}{T_{y}} \\
K_{E} & 0 & 0 & 0
\end{array}\right]
\end{aligned}
$$

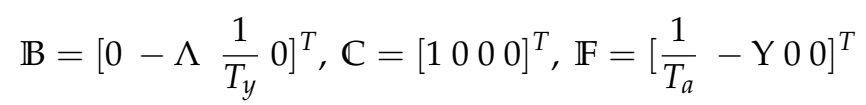

Appendix B. Proof of Theorem 3.1

Proof. According to Figure 3, we can have the following block diagram of the governing system in Figure A1a. Define $\Delta=G_{2}(s)-G_{2 r}(s)$ as the error between the original system and the reduced-order one. Then, the block diagram in Figure A1b is obtained. We can simplify the block diagram shown in Figure A1b by block diagram algebra. This precess is illustrated in Figure A2, where $\delta=\frac{\Delta}{G_{2 r}(s)}$.

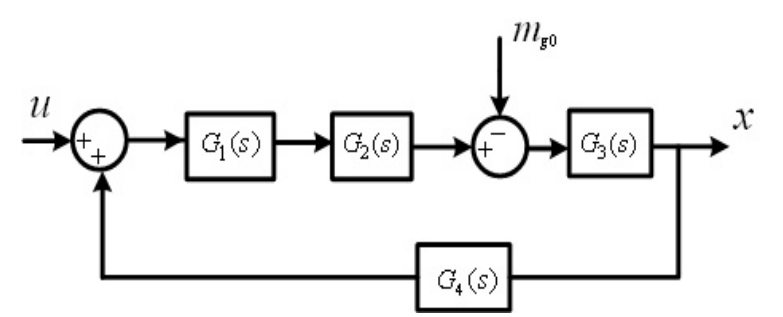

(a)

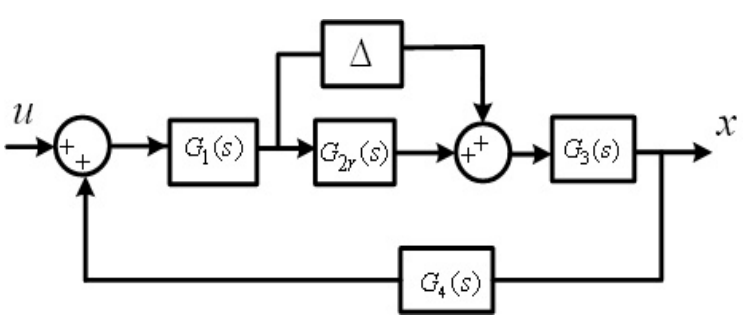

(b)

Figure A1. Block diagram. (a) The original governing system; (b) The reduced-order governing system with error.

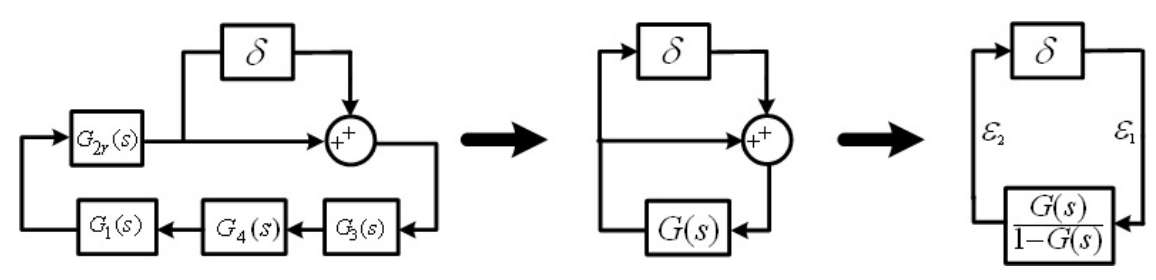

Figure A2. Simplification of the reduced-order system with error by block diagram algebra.

From the precess of designing the reduced-order sliding mode governor, we have known that the governor is able to asymptotically stabilize the reduced-order model, i.e., under the action of $u$ in Figure A1, $\frac{G(s)}{1-G(s)}$ has input-output stability with respect to the input $\varepsilon_{1}$ and the output $\varepsilon_{2}$. Equation (A1) can be obtained in the frequency domain.

$$
\varepsilon_{2}(s)=W(s) \varepsilon_{1}(s) \text { and } \varepsilon_{1}(s)=\delta(s) \varepsilon_{2}(s)
$$


here, $W(s)=\frac{G(s)}{1-G(s)}$. On account of the small gain theorem [32], a sufficient condition for stabilizing the interconnected system in Figure A2 is:

$$
\|\delta(s) \cdot W(s)\|_{\infty} \leq 1
$$

this indicates that the reduced-order sliding mode governor possesses the ability to stabilize the original system if Equation (A2) is satisfied. Further, Equation (A3) can be obtained according to the Cauchy-Schwarz inequality:

$$
\|\delta(s)\|_{\infty} \leq \frac{1}{\|W(s)\|_{\infty}}
$$

thus, Equation (24) can be drawn from Equation (A3).

\section{References}

1. Cuellar, A.D.; Herzog, H. A path forward for low carbon power from biomass. Energies 2015, 8, 1701-1715.

2. Rahi, O.P.; Chandel, A.K. Refurbishment and uprating of hydro power plants-A literature review. Renew. Sustain. Energy Rev. 2015, 48, 726-737.

3. Nagode, K.; Skrjanc, I. Modelling and internal fuzzy model power control of a Francis water turbine. Energies 2014, 7, 874-889.

4. Kishor, N.; Saini, R.P.; Singh, S.P. A review on hydropower plant models and control. Renew. Sustain. Energy Rev. 2007, 11, 776-796.

5. Fang, H.Q.; Chen, L.; Dlakavu, N.; Shen, Z.Y. Basic modeling and simulation tool for analysis of hydraulic transients in hydroelectric power plants. IEEE Trans. Energy Convers. 2008, 23, 834-841.

6. Natarajan, K. Robust PID controller design for hydroturbines. IEEE Trans. Energy Convers. 2005, 20, 661-667.

7. Jiang, C.W.; Ma, Y.C.; Wang, C.M. PID controller parameters optimization of hydro-turbine governing systems using deterministic-chaotic-mutation evolutionary programming (DCMEP). Energy Convers. Manag. 2006, 47, 1222-1230.

8. Fang, H.; Chen, L.; Shen, Z. Application of an improved PSO algorithm to optimal tuning of PID gains for water turbine governor. Energy Convers. Manag. 2011, 52, 1763-1770.

9. Husek, P. PID controller design for hydraulic turbine based on sensitivity margin specifications. Int. J. Electr. Power Energy Syst. 2014, 55, 460-466.

10. Jones, D.; Mansoor, S. Predictive feedforward control for a hydroelectric plant. IEEE Trans. Control Syst. Technol. 2004, 12, 956-965.

11. Kishor, N.; Singh, S.P. Simulated response of $\mathrm{NN}$ based identification and predictive control of hydro plant. Expert Syst. Appl. 2007, 32, 233-244.

12. Mahmoud, M.; Dutton, K.; Denman, M. Design and simulation of a nonlinear fuzzy controller for a hydropower plant. Electr. Power Syst. Res. 2005, 73, 87-99.

13. Jiang, J. Design of an optimal robust governor for hydraulic turbine generating units. IEEE Trans. Energy Convers. 1995, 10, 188-194.

14. Qian, D.; Yi, J. $\mathscr{L}_{1}$ adaptive governor design for hydro-turbines. ICIC Express Lett. Part B Appl. 2013, 3, $1171-117$.

15. Ding, X.; Sinha, A. Sliding mode $/ H_{\infty}$ control of a hydro-power plant. In Proceedings of the American Control Conference, San Francisco, CA, USA, 29 June-1 July 2011.

16. Salhi, I.; Doubabi, S.; Essounbouli, N.; Hamzaoui, A. Application of multi-model control with fuzzy switching to a micro hydro-electrical power plant. Renewv. Energy 2010, 35, 2071-2079.

17. Qian, D.W.; Zhao, D.B.; Yi, J.Q.; Liu, X.J. Neural sliding-mode load frequency controller design of power systems. Neural Comput. Appl. 2013 22, 279-286.

18. Erschler, J.; Roubellat, F.; Vernhes, J.P. Automation of a hydroelectric power station using variable-structure control systems. Automatica 1974, 10, 31-36.

19. Ye, L.Q.; Wei, S.P.; Xu, H.B.; Malik, O.P.; Hope, G.S. Variable structure and time-varying parameter control for hydroelectric generating unit. IEEE Trans. Energy Convers. 1989, 4, 293-299. 
20. Jing, L.; Ye, L.Q.; Malik, O.P.; Zeng, Y. An intelligent discontinuous control strategy for hydroelectric generating unit. IEEE Trans. Energy Convers. 1998, 13, 84-89.

21. Hydraulic Turbine and Turbine Control Models for System Dynamic Studies. Available online: http:/ /ieeexplore.ieee.org/xpl/articleDetails.jsp?tp=\&arnumber=141700 (accessed on 23 November 2015)

22. Qian, D.; Yi, J.; Liu, X. Design of reduced order sliding mode governor for hydro-turbines. In Proceedings of the American Control Conference, San Francisco, CA, USA, 29 June-1 July 2011.

23. Kendir, T.E.; Ozdamar, A. Numerical and experimental investigation of optimum surge tank forms in hydroelectric power plants. Renew. Energy 2013, 60, 323-331.

24. Chen, D.; Ding, C.; Ma, X.; Yuan, P.; Ba, D. Nonlinear dynamical analysis of hydro-turbine governing system with a surge tank. Appl. Math. Model. 2013, 37, 7611-7623.

25. Ghidaoui, M.S.; Zhao, M.; McInnis, D.A.; Axworthy, D.H.; McInnis, D.A. A review of water hammer theory and practice. Appl. Mech. Rev. 2005, 58, 49-76.

26. Sanathanan, C.K. Accurate Low Order Model for Hydraulic Turbine-Penstock. IEEE Trans. Energy Convers. 1987, 2, 196-200.

27. Doan, R.E.; Natarajan, K. Modeling and control design for governing hydroelectric turbines with leaky Wicket gates. IEEE Trans. Energy Convers. 2004, 19, 449-455.

28. Tan, W. Unified tuning of PID load frequency controller for power systems via IMC. IEEE Trans. Power Syst. 2010, 25, 341-350.

29. Cheng, L.; Hou, Z.G.; Lin, Y.Z.; Tan, M.; Zhang, W.C.; Wu, F.X. Recurrent neural network for non-smooth convex optimization problems with application to the identification of genetic regulatory networks. IEEE Trans. Neural Netw. 2011, 22, 714-726.

30. Tan, W. Analysis and design of a double two-degree-of-freedom control scheme. ISA Trans. 2010, 49, 311-317.

31. Streeter, V.L.; Wylie, B.E. Fluid Mechanics; McGraw-Hill: New York, NY, USA, 1979.

32. Khalil, H.K. Nonlinear Systems, 3rd ed.; Prentice Hall: Upper Saddle River, NJ, USA, 2002.

(C) 2015 by the authors; licensee MDPI, Basel, Switzerland. This article is an open access article distributed under the terms and conditions of the Creative Commons by Attribution (CC-BY) license (http:/ / creativecommons.org/licenses/by/4.0/). 